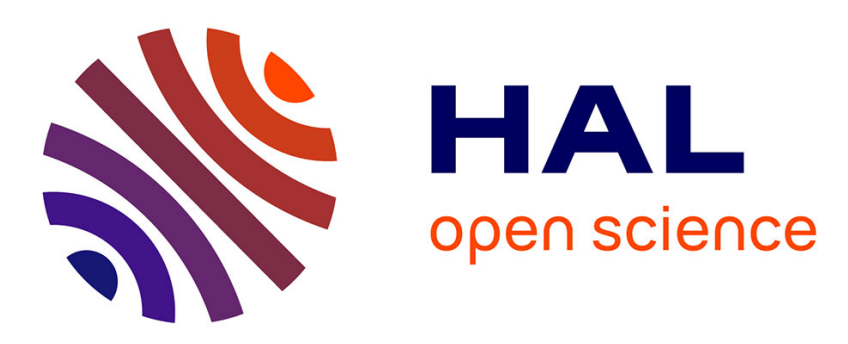

\title{
Tandem reactions of organnometallic reagents with a combined aminonitrile-oxazolidine system
}

Marc Le Bail, J. Perard-Viret, David J Aitken, Martine Bonin, Henri-Philippe Husson

\section{- To cite this version:}

Marc Le Bail, J. Perard-Viret, David J Aitken, Martine Bonin, Henri-Philippe Husson. Tandem reactions of organnometallic reagents with a combined aminonitrile-oxazolidine system. Tetrahedron Letters, 1997, 38 (41), pp.7177-7180. 10.1016/S0040-4039(97)01704-8 . hal-03376790

\section{HAL Id: hal-03376790 https://hal.science/hal-03376790}

Submitted on 13 Oct 2021

HAL is a multi-disciplinary open access archive for the deposit and dissemination of scientific research documents, whether they are published or not. The documents may come from teaching and research institutions in France or abroad, or from public or private research centers.
L'archive ouverte pluridisciplinaire HAL, est destinée au dépôt et à la diffusion de documents scientifiques de niveau recherche, publiés ou non, émanant des établissements d'enseignement et de recherche français ou étrangers, des laboratoires publics ou privés. 


\title{
Tandem Reactions of Organometallic Reagents with a Combined Aminonitrile-Oxazolidine System
}

\author{
Marc Le Bail, Joëlle Pérard, David J. Aitken,* Martine Bonin and Henri-Philippe Husson \\ Laboratoire de Chimie Thérapeutique associé au CNRS, Faculté des Sciences Pharmaceutiques et Biologiques, \\ Université René Descartes, 4 Avenue de l'Observatoire, 75270 Paris cedex 06, France.
}

\begin{abstract}
The reaction of the model combined aminonitrile-oxazolidine system 1 with a variety of Grignard and other organometallic reagents leads to the heterocyclic structures 3-imidazolines 2 and 2 aminomorpholines 3 by tandem addition/substitution reactions. The regioselectivity of the initial attack, and hence the relative proportions of products, varies with the nature of the reagent and the presence of Lewis acidity in the mixture.
\end{abstract}

Over the past decade our Laboratory has developed a variety of $N$-(cyanomethyl)oxazolidine derivatives as building blocks for biologically interesting nitrogen-containing compounds. 1 The original $(R)-N-$ cyanomethyl-4-phenyloxazolidine 1 has proved to be a versatile small chiral non-racemic molecule, having three types of nitrogen functional groups with differential reactivities: aminonitrile, aminoether and benzylic amine. To date, the following reactivities have been investigated (Scheme 1). Compound 1 can be deprotonated with strong base and alkylated stereoselectively with various electrophiles, giving an asymmetric route to aminoacids, aminoalcohols and amines. ${ }^{2}$ The tricarbonylchromium(0) complex of 1 can also be deprotonated, and the metalloarene system acts as an internal electrophile, inducing cyclization to give an isoindoline system. ${ }^{3}$ The aminoether function of the oxazolidine ring provides an iminium system when treated with a Lewis acid, and the facile subsequent deprotonation of the aminonitrile $\alpha$-carbon gives an azomethine ylide which undergoes 1,3-dipolar cycloaddition with olefins to give enantiomerically enriched pyrrolidine derivatives. ${ }^{4}$ The potential iminium reactivity of the aminoether moiety has also been invoked in the monoelectronic oxidation of a derivative of 1 to give a lactam. ${ }^{5}$

We reasoned that 1 should also be an interesting candidate for reactions with organometallic reagents. Depending on the nature of the reactants, aminonitriles can undergo a variety of different reactions with organometallics, ${ }^{6}$ including alkyl or hydride substitution reactions via an iminium ion, addition to the nitrile, and deprotonation. Oxazolidines usually give ring-opening substitution reactions with organometallic compounds. ${ }^{7}$ The reaction of an organometallic reagent with a combined oxazolidine-aminonitrile system, however, has been reported for only one special case. 8

\section{Scheme 1}<smiles>N#CN1COC[C@H]1c1ccccc1</smiles>

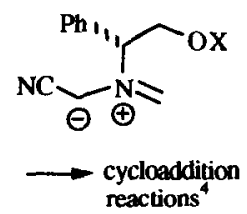

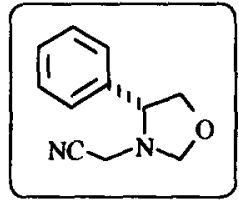

1

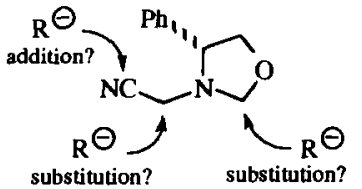

possible reactions with $\mathbf{R}-\mathbf{M}$ (this work)

Herein we report on a detailed study of the reactions of 1 with a variety of commonly-used Grignard and other organometallic reagents (in ether solution, $-70^{\circ} \mathrm{C}, 3-6 \mathrm{~h}$ ), which lead to interesting heterocyclic structures by virtue of the dual potential reactivity inherent in the system. In all cases, commercially available reagent solutions were used as supplied (after titration), except for Gilman cuprates which were prepared in situ from $\mathrm{CuI}$ and the corresponding organolithium compound. 
Reaction with Grignard reagents. Results of these studies are summarized in the Table. ${ }^{9}$ Treatment of 1 with two equivalents of Grignard reagent gave a clean reaction from which two new products were isolated easily by chromatography. With primary alkyl or aryl magnesium halides, 3 -imidazolines 2 a-c incorporating one Grignard-derived alkyl or aryl group at the 4-position were obtained as the major products $(37-55 \%)$. Also isolated (17-24\%) were 2-aminomorpholines 3a-c bearing two Grignard-derived functions, in which one anomeric form predominated $(>90 \%)$. A simple consideration of steric and anomeric effects suggests the most likely configuration of compounds 3 to be that with an axial amino-group, as shown (Scheme 2). With benzyl Grignard reagent, the 2-aminomorpholine $3 \mathrm{f}$ was the major product $(30 \%)$, and the yield of 3 imidazoline $2 \mathrm{f}$ was somewhat lower $(21 \%)$. The use of excess reagent in all the above reactions clearly facilitated the formation of 3 , but was necessary in order to achieve good conversion of 1 , probably due to partial reagent loss through dimerization. 10 Thus when only one equivalent of $\mathrm{PhMgBr}$ or $n$ - $\mathrm{BuMgCl}$ was used, 2-aminomorpholine formation was supressed, but the 3-imidazoline yields also dropped and starting material was recovered. On the other hand, when ten equivalents of $n-\mathrm{BuMgCl}$ were used, the yield of $3 \mathrm{c}$ more than doubled (to $40 \%$ ) while that of $2 \mathrm{c}$ diminished. The reactions of more sterically hindered Grignard reagents were less successful: treatment of 1 with two equivalents of $s-\mathrm{BuMgCl}$ gave only $21 \%$ of the 3imidazoline $2 \mathrm{~d}$ (and no 2-aminomorpholine), while $t$ - $\mathrm{BuMgCl}$ failed to give any reaction at all.

The possible mechanisms operating in these reactions are shown in Scheme 2. The formation of 2 is reminiscent of the reaction of Grignard reagents with $\omega$-halonitriles to give cyclic imines, ${ }^{11}$ and begins with selective addition of the organometallic reagent to the nitrile group of 1 . The intermediate $I$ undergoes intramolecular substitution at the oxazoline 2-position to give II, producing the new heterocyclic system. The transformation of $\mathbf{I}$ to $\mathbf{I}$ is irreversible, as was shown by treating a sample of $2 \mathbf{c}$ with excess $n-\mathrm{BuMgCl}$, from which $2 \mathbf{c}$ was recovered unreacted with no trace of $3 \mathbf{c}$.

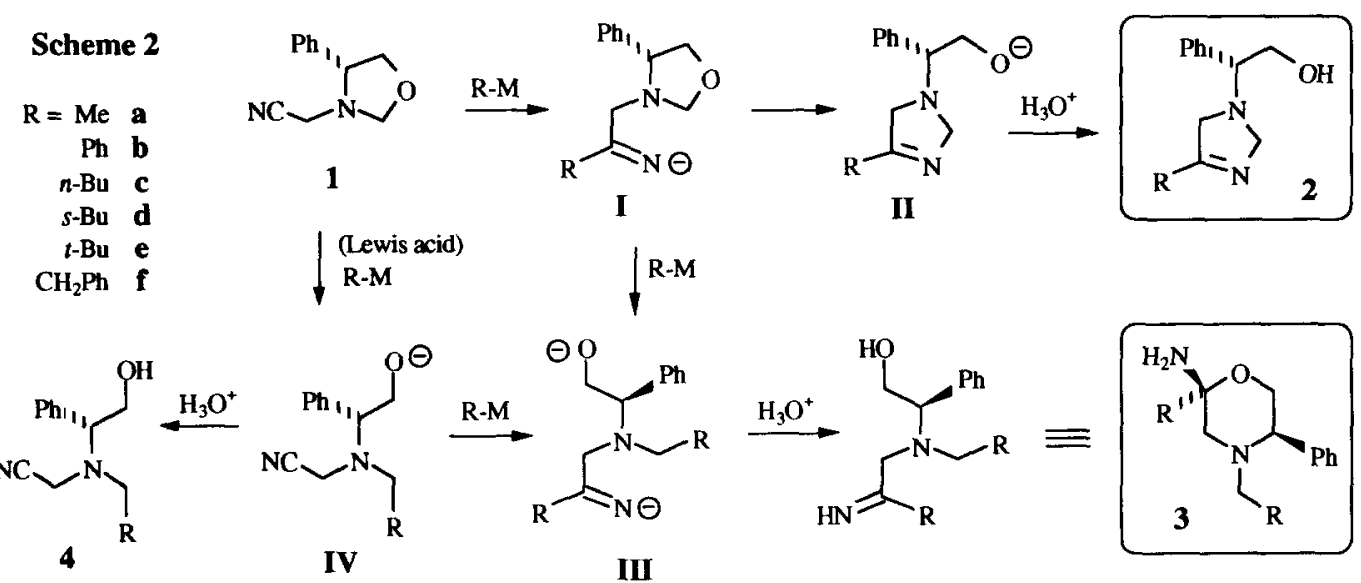

There are two possible explanations for the formation of 3 . Intermolecular attack of the oxazolidine of I by a second carbon nucleophile may be competitive when the organometallic reagent is in excess, leading to III which cyclizes to 3 spontaneously upon work-up. However, an alternative route to III via IV, implying regioselective inital attack at the oxazolidine ring, cannot be discounted. The inherent Lewis acidity in Grignard preparations may be sufficient to promote this reactivity, and it was interesting to note that the benzyl reagent, which was the most prone to dimerization and therefore release of $\mathrm{MgCl}_{2}$, gave the greatest 3:2 product ratio. Observation of the single substitution products 4 would have supported this suggestion, but only traces were found (highest yield $5 \%$, for $\mathbf{4 f}$ ). Nonetheless, following this argument, it was possible to change dramatically the regioselectivity and privilege the formation of an intermediate IV, by carrying out the reaction of 1 with a Grignard reagent in the presence of an external Lewis acid. Thus an equimolar mixture of 
Table Products and yields $(\%)$ in the reaction of 1 with Grignard reagents

\begin{tabular}{cccc}
\hline Reagent $^{\mathrm{a}}$ & recovered 1 & 2 & 3 \\
\hline $\mathrm{MeMgX}^{\mathrm{b}}$ & - & 37 & 24 \\
$\mathrm{PhMgBr}$ & - & 55 & 24 \\
$n-\mathrm{BuMgCl}$ & - & 44 & 17 \\
$\mathrm{PhCH} \mathbf{M g g C l}^{\mathrm{M}}$ & - & 21 & 30 \\
$s-\mathrm{BuMgCl}$ & 10 & 21 & - \\
$t-\mathrm{BuMgCl}$ & 87 & - & - \\
$\mathrm{PhMgBr}(1$ eq. $)$ & 40 & 22 & - \\
$n-\mathrm{BuMgCl}(1$ eq. $)$ & 51 & 17 & - \\
$n-\mathrm{BuMgCl}(10$ eq. $)$ & - & 18 & 40 \\
$\mathrm{PhMgBr}(5 \text { eq. })^{c}$ & - & - & 55 \\
$n-\mathrm{BuMgBr}(5 \text { eq. })^{c}$ & - & - & 52 \\
\hline
\end{tabular}

a: two equivalents unless otherwise indicated b: similar results obtained for both $\mathrm{X}=\mathrm{Cl}$ and $\mathrm{Br}$ c: 1 equiv. $\mathrm{AlCl}_{3}$ added before the Grignand reagent

\section{Scheme 3}<smiles>CCN(CC)C(CO)Cc1ccccc1</smiles>

\section{Scheme 4}<smiles>CN(CC(=O)c1ccccc1)C(CO)CO</smiles>

1 and $\mathrm{AlCl}_{3}$ was treated with five equivalents of $\mathrm{PhMgBr}$ or $n-\mathrm{BuMgCl}$ to give $3 \mathrm{~b}$ and $3 \mathrm{c}$ respectively as single products in $>50 \%$ yield. It was also interesting to note that the reaction of 1 with two equivalents of Mes Al furnished $4 \mathbf{a}(62 \%)$, accompanied by a small amount (15\%) of the Bruylants nitrile-substitution product $N, N$-diethylphenylglycinol 5 (Scheme 3 ).

Comparison with organolithium reagents and Gilman cuprates. Reactions of 1 with two equivalents of these reagents followed modified reactivity patterns, but were less clean than for Grignard reagents, leading to complex product mixtures.

With $\mathrm{RLi}(\mathrm{R}=\mathrm{Me}, \mathrm{Ph}, n-\mathrm{Bu}, s-\mathrm{Bu}, t-\mathrm{Bu})$, it was not possible to isolate any 2-aminomorpholines 3, and analysis of the NMR spectra of the crude product mixture gave no firm evidence for their formation; this would be consistent with the lower Lewis acidity of organolithium preparations. The 3-imidazolines 2a-c were isolated from their respective product mixtures in yields (25-32\%) which were in general slightly lower than those obtained with the corresponding Grignard reagent, although this situation was inversed for the more bulky reagents $s-\mathrm{BuLi}$ and $t-\mathrm{BuLi}$, which gave $2 \mathrm{~d}(35 \%)$ and $2 \mathrm{e}(44 \%)$ respectively.

From reactions of 1 with $\mathrm{R}_{2} \mathrm{CuLi}(\mathrm{R}=\mathrm{Me}, \mathrm{Ph}, n$-Bu), 3-imidazolines $2 \mathrm{a}-\mathrm{c}$ were isolated in low yield $(15-25 \%)$. Taking the case of $n-\mathrm{Bu}_{2} \mathrm{CuLi}$ as representative, the product mixture was separated carefully to give, in addition to $2 \mathrm{c}(25 \%), 2$-aminomorpholine $3 \mathrm{c}$ (24\%) and a new 2-aminomorpholine 6c (25\%) (Scheme 4). Cuprate preparations are sometimes contaminated with a species termed "CuH" which behaves as a reducing agent, ${ }^{12}$ and the formation of structure $6 c$ can be explained by the reduction of the oxazolidine system of Ic to give Vc.

Conclusions. This study suggests that Lewis acidity is a determining factor in the tandem reactions of common organometallic reagents with a combined aminonitrile-oxazolidine system. Depending on the nature of the reagent, either of two original heterocyclic structures 2 and 3 can be prepared. In contrast with the well-known 2-imidazolines, there are very few literature methods ${ }^{13,14}$ for the preparation of 3 -imidazolines 2 , and their chemical and biological properties are almost unknown. 15 Likewise, 2-aminomorpholines 3 have not been described previously. These observations present considerable scope for further work and exploitation, and the chemical reactivities and synthetic potential of the above-described compounds are currently under investigation. 
Acknowledgement. This work was supported by CNRS and Rhône-Poulenc-Rorer through the BioAvenir programme (a grant to M.L.B.)

\section{References and Notes.}

1. (a) Husson, H.-P.; Royer, J. In Advances in the Use of Synthons in Organic Chemistry, Vol. 2, Dondoni, A., ed., JAI Press, Greenwich, 1995; pp 1-68 (b) Husson, H.-P. In New Aspects of Organic Chemistry II, Yoshida, Z.; Ohshiro, Y. eds., VCH, Basel, 1992; pp 87-103.

2. (a) Aitken, D. J.; Royer, J.; Husson, H.-P. J. Org. Chem., 1990, 55, 2814-2820 (b) Aitken, D. J.; Royer, J.; Husson, H.-P. Tetrahedron Lett., 1988, 29, 3315-3318 (c) Marco, J. L.; Royer, J.; Husson, H.-P. Synth. Commun., 1987, 17, 669-676 (d) Marco, J. L.; Royer, J.; Husson, H.-P. Tetrahedron Lett., 1985, 26, 6345-6348 (e) Marco, J. L.; Royer, J.; Husson, H.-P. Tetrahedron Lett., 1985, 26, 3567-3570.

3. Besson, L.; Le Bail, M.; Aitken, D. J.; Husson, H.-P.; Rose-Munch, F.; Rose, E. Tetrahedron Lett., 1996, 37 , 3307-3308.

4. (a) Deprez, P.; Royer, J.; Husson, H.-P. Tetrahedron, 1993, 49, 3781 -3782 (b) Deprez, P.; Royer, J.; Husson, H.-P. Tetrahedron: Asymmetry, 1991, 2, 1189-1192 (c) Deprez, P.; Royer, J.; Husson, H.-P. Synthesis, 1991, 759-762 (d) Rouden, J.; Royer, J.; Husson, H.-P. Tetrahedron Lett., 1989, 30, 5133-5136.

5. Billon-Souquet, F.; Martens, T.; Royer, J. Tetrahedron, 1996, 52, 15127-15136.

6. For leading references, see: (a) Shafran, Y. M.; Bakulev, V. A.; Mokrushin, V. S. Russ. Chem. Rev., 1989, 58, 148-162 (b) Rubiralta, M.; Giralt, E.; Diez, A. Piperidine, Elsevier, Amsterdam, 1991: pp 225-312 (c) Ahlbrecht, H.; Dollinger, H. Synthesis, 1985, 743-748 (d) Thies, H.; Schönenberger, H.; Qasba, P. K. Arch. Pharm. (Weinheim), 1969, 302, 30-42 (d) Chauvière, G.; Tchoubar, B.; Welvart, Z. Bull. Soc. Chim. Fr., 1963, 1428-1433 (e) Schröter, R. In Methoden der Organischen Chemie (Houben-Weyl), Müller, E., ed., Thieme Verlag, Stuttgart, 1957, vol. XI; p 562. For related work and further useful references, see: Katritzky, A. R.; Latif, M.; Urogdi, L. J. Chem. Soc., Perkin Trans. I, 1990, 667-672.

7. For examples, see: (a) Pridgen, L. N.; Mokhallalati, M. K.; McGuire, M. A. Tetrahedron Lett., 1997, $38,1275-$ 1278 (b) Higashiyama, K.; Inoue, H.; Yamauchi, T.; Takahashi, H. J. Chem. Soc., Perkin Trans. I, 1995, 111115 (c) Higashiyama, K.; Inoue, T.; Takahashi, H. Tetrahedron, 1994, 50, 1083-1092 (d) Pridgen, L. N.; Mokhallalati, M. K.; Wu, M.-J. J. Org. Chem., 1992, 57, $1237-1241$ (e) Andrés, C.; González, A.; Pedrosa, R.; Pérez-Encabo, A. Tetrahedron Lett., 1992, 33, 2895-2898 (f) Royer, J.; Husson, H.-P. Tetrahedron Lett., 1985, 26, 1515-1518.

8. (a) Froelich, O.; Desos, P.; Bonin, M.; Quirion, J.-C.; Husson, H.-P.; Zhu, J. J. Org. Chem., 1996, 61, 6700-6705 (b) Zhu, J.; Quirion, J.-C.; Husson, H.-P. J. Org. Chem., 1993, 58, 6451-6456.

9. All new products showed satisfactory spectral and/or analytical data.

10. The formation of the non-volatile Wurtz-coupling by-products biphenyl and 1,2-diphenylethane was observed in reactions involving phenyl and benzyl Grignards, respectively. In one case ( $\mathrm{PhMgBr}$ ) the reaction was repeated with slow addition (2-3h) of the Grignard in an effort to supress this phenomenon, without any significant change in product yields.

11. (a) Fry, D. F.; Brown, M.; McDonald, J. C.; Dieter, R. K. Tetrahedron Lett., 1996, 37, 6227-6230 (b) Fry, D. F.; Fowler, C. B.; Dieter, R. K. Synlett, 1994, 836-838 (c) Larchevêque, M.; Debal, A.; Cuvigny, T. Bull. Soc. Chim. Fr., 1974, 1710-1714 (d) Meyers, A. I.; Sircar, J. C. In The Chemistry of the Cyano Group, Patai, S., ed., Wiley, New York, 1970; pp 341-422.

12. (a) Captain, L. F.; Xia, X.; Liotta, D. C. Tetrahedron Lett., 1996, 37, 4293-4296 (b) Lipshutz, B. H.; Wilhelm, R. S.; Kozlowski, J. A. Tetrahedron, 1984, 40, $5005-5038$ (c) House, H. O.; Wilkins, J. M. J. Org. Chem., 1978, 43, 2443-2454.

13. Literature methods: (a) Kirchner, G. Liebigs Ann. Chem., 1959, 625, 98-103 and 104-107 (b) Asinger, F.; Thiel, M.; Sowada, R. Monatsh. Chem., 1959, 90, 402-416.

14. Other reports of 3-imidazolines: (a) Derstine, C. W.; Smith, D. N.; Katzenellenbogen, J. A. J. Am. Chem. Soc., 1996, 118, 8485-8486 (b) Marchand, A. P.; Rajagopal, D.; Bott, S. G. J. Heterocyclic Chem., 1995, 32, 14091411 (c) Chiba, T.; Sakagami, H.; Murata, M.; Okimoto, M. J. Org. Chem., 1995, 60, 6764-6770 (c) Flammang, R.; Lacomb, S.; Laurent, A.; Maquestiau, A.; Marquet, B.; Novkova, S. Tetrahedron, 1986, 42, 315 328 (d) Kauffmann, T.; Busch, A.; Habersaat, K.; Kobpelmann, E. Chem. Ber., 1983, 116, $492-499$ (e) Katritzky, A. R.; Bravo Borja, S.; Marquet, J.; Sammes, M. P. J. Chem. Soc., Perkin Trans. I, 1983, 2065-2069 (f) Gavin, J. P.; Waigh, R. D. J. Chem. Soc., Perkin Trans I, 1990, 503-508 and references therein

15. N-Oxygenated derivatives are well known: (a) Volodarsky, L. B., ed.; Synthetic Chemistry of Stable Nitroxides, CRC Press, Boca Raton, 1994 (b) Volodarsky, L. B., ed.; Imidazoline Nitroxides, CRC Press, Boca Raton, 1988. 